\title{
PENGARUH KOMPETENSI, DISIPLIN KERJA, DAN MOTIVASI KERJA TERHADAP KINERJA PEGAWAI
}

\author{
${ }^{1}$ Wike Pertiwi, ${ }^{2}$ Citra Savitri \\ ${ }^{12}$ Universitas Buana Perjuangan Karawang \\ email: ${ }^{1}$ wike.pertiwi@ubpkarawang.ac.id ,2 ${ }^{2}$ citra.savitri@ubpkarawang.ac.id
}

\begin{abstract}
ABSTRAK
Tujuan penelitian ini untuk mengetahui dan menjelaskan pengaruh kompetensi, disiplin kerja, dan motivasi kerja terhadap kinerja pegawai. Penelitian ini menggunakan pendekatan kuantitatif. Metode survei dipilih sebagai sumber data primer. Pengumpulan data dilakukan menggunakan instrumen kuesioner atau angket. Berdasarkan tingkat eksplanasinya, tergolong sebagai penelitian asosiatif. Objek pada penelitian ini adalah pegawai salahsatu Dinas di Kab. Cirebon. Alasan mengambil objek penelitian ini karena ingin mengetahui faktor-faktor yang paling berpengaruh terhadap kinerja pegawai dalam pencapaian tujuan, yaitu untuk meningkatkan pelayanan terhadap masyarakat terutama dalam proses pengawasan dan pembinaan terhadap kebutuhan informasi. Jumlah populasi pada penelitian ini adalah seluruh Pegawai Bagian Humas Dan Bagian Umum Setda Kabupaten Cirebon yang berjumlah 40 orang. Sampel yang diambil dalam penelitian ini adalah sampel jenuh atau seluruh populasi yaitu sebanyak 40 orang. Hasil penelitian ini menunjukkan Kompetensi memiliki pengaruh positif dan signifikan terhadap kinerja pegawai. Disiplin kerja memiliki pengaruh positif dan signifikan terhadap kinerja pegawai. Motivasi kerja memiliki pengaruh positif dan signifikan terhadap kinerja pegawai. Secara simultan, ketiga variabel yang diteliti yaitu kompetensi, disiplin kerja dan motivasi kerja bepengaruh positif dan signifikan terhadap kinerja pegawai.
\end{abstract}

Kata kunci: Kompetensi, Disiplin Kerja, Motivasi Kerja, dan Kinerja Pegawai

\begin{abstract}
The purpose of this study was to determine and explain the effect of competence, work discipline, and work motivation on employee performance. This study uses a quantitative approach. The survey method was chosen as the primary data source. Data collection was carried out using a questionnaire or questionnaire instrument. Based on the level of explanation, it is classified as associative research. The object of this research is an employee of one of the offices in the district. Cirebon. The reason for taking the object of this research is because they want to know the factors that have the most influence on employee performance in achieving goals, namely to improve services to the community, especially in the process of monitoring and fostering information needs. The total population in this study were all employees of the Public Relations Section and the General Section of the Cirebon Regency Secretariat, amounting to 40 people. The sample taken in this study was a saturated sample or the entire population as many as 40 people. The results of this study indicate that competence has a positive and significant effect on employee performance. Work discipline has a positive and significant effect on employee performance. Work motivation has a positive and significant effect on employee performance. Simultaneously, the three variables studied, namely competence, work discipline and work motivation have a positive and significant impact on employee performance.
\end{abstract}

Keywords: Competence, Work Discipline, Work Motivation, and Employee Performance 


\section{PENDAHULUAN}

Sebuah instansi atau organisasi harus memiliki pegawai yang memiliki pengetahuan dan keterampilan yang tinggi serta berusaha untuk mengelola organisasi. Menurut Choirul, kompetensi adalah segala bentuk perwujudan, ekspresi dan representasi dari motif, pengetahuan, sikap, dan perilaku utama pegawai agar mampu melaksanakan pekerjaan dengan sangat baik. Seorang pegawai memiliki kompetensi yang tinggi apabila pegawai tersebut memiliki pengalaman kerja, latar belakang pendidikan yang mendukung profesi, memiliki keahlian, pengetahuan, serta memiliki keterampilan. Selain kompetensi, disiplin juga termasuk faktor yang mempengaruhi kinerja pegawai. Menurut Sulistiyani, disiplin merupakan bentuk dari pengendalian diri pegawai dan pelaksanaan yang teratur dalam menunjukkan tingkat kesungguhan tim kerja dalam sebuah organisasi. (Sulistiyani,2013;236). Selain kompetensi dan disiplin, faktor yang juga mempengaruhi kinerja pegawai adalah motivasi kerja. Motivasi merupakan dorongan yang muncul dari dalam diri seorang individu untuk mengerjakan tugas yang diemban. Pegawai termotivasi untuk meningkatkan kinerja karena adanya dorongan yang kuat untuk memenuhi kebutuhan yang belum terpenuhi serta sebagai proses aktualisasi diri pegawai yang dibuktikan lewat kemampuan dalam mengemban tugas dan pekerjaan yang dibebankan. Kemajuan dan keberhasilan Instansi sangat tergantung pada kinerja individu dalam dalam hal ini pegawai, dimana pegawai tersebut mampu bekerja keras proaktif, loyal serta disiplin tinggi dan bertanggung jawab terhadap tugas dan pekerjaan yang pada akhirnya dapat mencapai kinerja yang optimal, sehingga berdampak positif pada kinerja Instansi. Namun pada kenyataannya masih ditemukan masalah yang berkaitan dengan kinerja pegawai. Salah satunya pelayanan yang kurang baik yang diterima oleh para pencari kerja. Maka upaya peningkatan kinerja sangat penting sehingga berpengaruh terhadap kinerja pelayanan publik/masyarakat. Maka kompetensi, disiplin dan motivasi pegawai sangat diperlukan untuk meningkatkan kinerja para pegawai.

\section{KAJIAN PUSTAKA}

\section{Kinerja}

Menurut Kumara dan Utama (2016) pengertian kinerja adalah pelayanan pengorbanan tubuh dan pikiran untuk menghasilkan barang atau jasa dalam pertukaran untuk memperoleh prestasi tertentu. Sinambela $(2012 ; 88)$ mengemukakan bahwa kinerja adalah pelaksanaan suatu pekerjaan dan penyempurnaan pekerjaan sesuai dengan tanggung jawabnya sehingga dapat mencapai hasinya. Mangkunegara (2011:67) menyatakan kinerja adalah hasil kerja secara 
kualitas dan kuantitas yang dicapai oleh seorang pegawai dalam melaksanakan tugasnya sesuai dengan tanggung jawab.

\section{Kompetensi}

Kompetensi menurut Wibowo (2013:324) adalah suatu kemampuan untuk melaksanakan atau melakukan suatu pekerjaan atau tugas yang dilandasi atas keterampilan dan pengetahuan serta didukung oleh sikap kerja yang dituntut oleh pekerjaan tersebut. Sedangkan menurut Mc Clelland dalam Veithzal Rivai dan Ella Jauvani Sagala (2011:299) kompetensi (competency) sebagai karakteristik yang mendasar yang dimiliki seseorang yang berpengaruh langsung terhadap, atau dapat memprediksikan, kinerja yang sangat baik.

\section{Disiplin}

Menurut Lijan Poltak Sinambela (2016:335) disiplin kerja adalah kemampuan kerja seseorang untuk secara teratur, tekun secara terus-menerus dan bekerja sesuai dengan aturanaturan berlaku dengan tidak melanggar aturan-aturan yang sudah ditetapkan. Para pegawai dapat bertindak dan berpartisipasi sesuai dengan norma-norma yang berlaku pada organisasi dan pegawai mampu menghasilkan produktivitas yang tinggi sesuai dengan harapan organisasi, baik dalam jangka pendek maupun jangka panjang (Rivai, 2015: 440).

\section{Motivasi Kerja}

Mangkunegara (2017:93) mengatakan bahwa Motivasi adalah suatu kondisi yang menggerakan manusia ke arah suatu tujuan tertentu. Mangkunegara menyatakan bahwa motivasi dapat disimpulkan sebagai berikut :

a. Kondisi yang menggerakan manusia ke arah suatu tujuan tertentu;

b. Keahlian dalam mengarahkan pegawai dan perusahaan agar mau bekerja dengan berhasil, sehingga keinginan pegawai dan tujuan perusahaan sekaligus dapat tercapai;

c. Sebagai inisiasi dan pengarahan tingkah laku, pelajaran motivasi sebenarnya merupakan pelajaran tingkah laku;

d. Sebagai energi untuk membangkitkan dorongan dalam diri;

Sebagai kondisi yang berpengaruh membangkitkan, mengarahkan dan memelihara perilaku yang berhubungan dengan lingkungan kerja.

\section{METODE PENELITIAN}


Penelitian ini menggunakan pendekatan kuantitatif. Metode survei dipilih sebagai sumber data primer. Pengumpulan data dilakukan menggunakan instrumen kuesioner atau angket. Berdasarkan tingkat eksplanasinya, tergolong sebagai penelitian asosiatif. Objek pada penelitian ini adalah pegawai salahsatu Dinas di Kab. Cirebon. Alasan mengambil objek penelitian ini karena ingin mengetahui faktor-faktor yang paling berpengaruh terhadap kinerja pegawai dalam pencapaian tujuan, yaitu untuk meningkatkan pelayanan terhadap masyarakat terutama dalam proses pengawasan dan pembinaan terhadap kebutuhan informasi.

\section{METODE PENGUMPULAN DATA}

Instrumen penelitian yang digunakan untuk mengumpulkan data terdiri atas, lembar kuesioner kinerja pegawai, kompensasi pegawai, disiplin pegawai, dan motivasi pegawai. Jumlah populasi pada penelitian ini adalah seluruh Pegawai Bagian Humas Dan Bagian Umum Setda Kabupaten Cirebon yang berjumlah 40 orang. Sampel yang diambil dalam penelitian ini adalah sampel jenuh atau seluruh populasi yaitu sebanyak 40 orang.

\section{HASIL PENELITIAN DAN PEMBAHASAN \\ HASIL PENELITIAN}

TEKNIK ANALISIS DATA

Uji Instrumen

Uji Validitas dan Realibilitas

Variabel X1 Kompetensi

Tabel 1. Validitas Variabel Kompetensi (X1)

\begin{tabular}{ll|l|l|l|}
\hline & $\begin{array}{l}\text { Scale Mean if Item } \\
\text { Deleted }\end{array}$ & $\begin{array}{l}\text { Scale } \\
\text { Variance } \\
\text { Item Deleted }\end{array}$ & $\begin{array}{l}\text { Corrected } \\
\text { Item-Total } \\
\text { Correlation }\end{array}$ & $\begin{array}{l}\text { Squared } \\
\text { Multiple } \\
\text { Correlation }\end{array}$ \\
\hline Kompetensi 01 & 36,78 & 4,281 &, 292 &, 427 \\
\hline Kompetensi 02 & 37,00 & 4,103 &, 302 &, 499 \\
\hline Kompetensi 03 & 36,95 & 4,151 &, 284 &, 428 \\
\hline Kompetensi 04 & 37,08 & 3,815 &, 456 &, 456 \\
\hline Kompetensi 05 & 36,85 & 4,336 &, 218 &, 355 \\
\hline Kompetensi 06 & 36,90 & 3,938 &, 417 &, 520 \\
\hline Kompetensi 07 & 37,00 & 4,103 &, 302 &, 455 \\
\hline Kompetensi 08 & 36,98 & 4,333 &, 347 &, 512 \\
\hline Kompetensi 09 & 36,88 & 3,907 &, 448 &, 409 \\
\hline
\end{tabular}


Berdasarkan hasil di atas, dapat dikatakan korelasi masing-masing butir kuesioner variabel memiliki nilai korelasi antar butir pertanyaan pada kolom Corrected Item-Total Correlation $\geq 0.2638$ ( $\mathrm{r}$ tabel) artinya keseluruhan instrumen penelitian variabel X1 memiliki nilai yang yang valid sehingga dapat digunakan untuk penelitian. Realibilitas variabel X1 Kompetensi dapat dilihat pada tabel berikut ini:

Tabel 2. Realibilitas Kompetensi (X1)

\begin{tabular}{l|l|l}
\hline Cronbach's Alpha & $\begin{array}{l}\text { Cronbach's Alpha Based on } \\
\text { Standardized Items }\end{array}$ & N of Items \\
\hline, 928 &, 931 & 9 \\
\hline
\end{tabular}

Dari tabel di atas, nilai Cronbach's Alpha 0,928 > 0,60 artinya data tersebut realiabel dan memenuhi syarat untuk dapat digunakan untuk penelitian sebagai instrumen variabel.

\section{Variabel X2 Disiplin}

Validitas variabel X2 dukungan didapat dilihat pada tabel berikut ini:

Tabel 3 Validitas Disiplin (X2)

\begin{tabular}{lr|r|r|r}
\hline $\begin{array}{l}\text { Scale Mean if Item } \\
\text { Deleted }\end{array}$ & $\begin{array}{r}\text { Scale Variance if Item } \\
\text { Deleted }\end{array}$ & $\begin{array}{r}\text { Corrected Item-Total } \\
\text { Correlation }\end{array}$ & $\begin{array}{c}\text { Squared Multiple } \\
\text { Correlation }\end{array}$ \\
\hline Disiplin 01 & 30,78 & 25,512 &, 710 &, 599 \\
\hline Disiplin 02 & 30,65 & 25,105 &, 780 &, 749 \\
\hline Disiplin 03 & 30,55 & 23,792 &, 705 &, 592 \\
\hline Disiplin 04 & 30,53 & 25,794 &, 759 &, 667 \\
\hline Disiplin 05 & 30,45 & 23,741 &, 792 &, 685 \\
\hline Disiplin 06 & 30,80 & 26,062 &, 786 &, 645 \\
\hline Disiplin 07 & 30,60 & 24,144 &, 759 &, 738 \\
\hline Disiplin 08 & 30,68 & 25,763 &, 785 &, 684 \\
\hline Disiplin 09 & 30,58 & 24,507 &, 726 \\
\hline
\end{tabular}

Berdasarkan hasil di atas, dapat dikatakan korelasi masing-masing butir kuesioner variabel memiliki nilai korelasi antar butir pertanyaan pada kolom Corrected Item-Total Correlation $\geq 0.2638$ ( $\mathrm{r}$ tabel) artinya keseluruhan instrumen penelitian variabel X2 memiliki nilai yang 
yang valid sehingga dapat digunakan untuk penelitian. Realibilitas variabel X2 disiplin dapat dilihat pada tabel berikut ini:

Tabel 4. Realibilitas Variabel Disiplin (X2)

\begin{tabular}{|r|r|r|}
\hline & $\begin{array}{c}\text { Cronbach's Alpha } \\
\text { Based on } \\
\text { Cronbach's Alpha }\end{array}$ & \\
\hline, 890 &, 897 & N of Items \\
\hline
\end{tabular}

Dari tabel di atas, nilai Cronbach's Alpha 0,890 > 0,60 artinya data tersebut reliabel dan memenuhi syarat untuk dapat digunakan untuk penelitian sebagai instrumen variabel.

\section{Variabel X3 Motivasi Kerja}

Validitas variabel X3 motivasi kerja dapat dilihat pada tabel berikut ini:

Tabel 5. Validitas Variabel Motivasi kerja (X3)

\begin{tabular}{lc|c|c|c}
\hline & $\begin{array}{c}\text { Scale Mean if Item } \\
\text { Deleted }\end{array}$ & $\begin{array}{c}\text { Scale Variance if } \\
\text { Item Deleted }\end{array}$ & $\begin{array}{c}\text { Corrected Item-Total } \\
\text { Correlation }\end{array}$ & $\begin{array}{c}\text { Squared Multiple } \\
\text { Correlation }\end{array}$ \\
\hline Motivasi kerja 01 & 37,08 & 5,199 &, 290 &, 131 \\
\hline Motivasi kerja 02 & 36,00 & 4,872 &, 285 &, 176 \\
\hline Motivasi kerja 03 & 35,90 & 5,477 &, 296 &, 202 \\
\hline Motivasi kerja 04 & 36,13 & 5,189 &, 536 &, 527 \\
\hline Motivasi kerja 05 & 36,10 & 4,708 &, 491 &, 592 \\
\hline Motivasi kerja 06 & 36,03 & 4,846 &, 418 &, 444 \\
\hline Motivasi kerja 07 & 36,13 & 4,933 &, 306 &, 557 \\
\hline Motivasi kerja 08 & 35,93 & 5,507 &, 547 &, 588 \\
\hline Motivasi kerja 09 & 36,13 & 4,676 & & \\
\hline
\end{tabular}

Berdasarkan hasil di atas, dapat dikatakan korelasi masing-masing butir kuesioner variabel memiliki nilai korelasi antar butir pertanyaan pada kolom Corrected Item-Total Correlation $\geq 0.2638$ ( $\mathrm{r}$ tabel) artinya keseluruhan instrumen penelitian variabel X3 memiliki nilai yang 
yang valid sehingga dapat digunakan untuk penelitian. Realibilitas variabel X3 motivasi kerja dapat dilihat pada tabel berikut ini:

Tabel 6. Realibilitas Variabel Motivasi kerja (X3)

\begin{tabular}{r|r|r}
\hline \multicolumn{2}{c}{ Reliability Statistics } \\
Cronbach's Alpha & $\begin{array}{c}\text { Cronbach's Alpha } \\
\text { Based on } \\
\text { Standardized Items }\end{array}$ & N of Items \\
\hline, 757 &, 784 & \\
\hline
\end{tabular}

Dari tabel di atas, nilai Cronbach's Alpha 0,757>0,60 artinya data tersebut reliabel dan memenuhi syarat untuk dapat digunakan untuk penelitian sebagai instrumen variabel.

\section{Variabel Y Kinerja Pegawai}

Validitas variabel Y kinerja dapat dilihat pada tabel berikut ini:

Tabel 7. Validitas Variabel Kinerja (Y)

\begin{tabular}{lc|c|c|c|}
\hline & $\begin{array}{c}\text { Scale Mean if Item } \\
\text { Deleted }\end{array}$ & $\begin{array}{c}\text { Scale Variance if } \\
\text { Item Deleted }\end{array}$ & $\begin{array}{c}\text { Corrected Item- } \\
\text { Total Correlation }\end{array}$ & $\begin{array}{c}\text { Squared Multiple } \\
\text { Correlation }\end{array}$ \\
\hline Kinerja 01 & 36,85 & 4,695 &, 450 &, 373 \\
\hline Kinerja 02 & 36,93 & 4,481 &, 532 &, 448 \\
\hline Kinerja 03 & 36,95 & 4,562 &, 483 &, 454 \\
\hline Kinerja 04 & 36,93 & 4,430 &, 328 &, 509 \\
\hline Kinerja 05 & 36,95 & 4,869 &, 292 &, 442 \\
\hline Kinerja 06 & 36,88 & 5,189 &, 290 &, 196 \\
\hline Kinerja 07 & 37,08 & 4,943 &, 395 &, 414 \\
\hline Kinerja 08 & 36,88 & 4,779 &, 278 &, 302 \\
\hline Kinerja 09 & 36,78 & 5,102 & & \\
\hline
\end{tabular}

Berdasarkan hasil di atas, dapat dikatakan korelasi masing-masing butir kuesioner variabel memiliki nilai korelasi antar butir pertanyaan pada kolom Corrected Item-Total Correlation $\geq 0.2638$ ( $\mathrm{r}$ tabel) artinya keseluruhan instrumen penelitian variabel Y memiliki nilai yang yang 
valid sehingga dapat digunakan untuk penelitian. Realibilitas variabel Y Kinerja dapat dilihat pada tabel berikut ini:

Tabel 8. Realibilitas Variabel Kinerja (Y)

\begin{tabular}{r|r|r}
\hline & $\begin{array}{c}\text { Cronbach's Alpha } \\
\text { Based on } \\
\text { Cronbach's Alpha }\end{array}$ & Standardized Items \\
\hline, 715 & N of Items \\
\hline
\end{tabular}

Dari tabel di atas, nilai Cronbach's Alpha 0,715 >0,60 artinya data tersebut reliabel dan memenuhi syarat untuk dapat digunakan untuk penelitian sebagai instrumen variabel.

\section{Uji Normalitas}

Tabel 9. Uji Normalitas

\begin{tabular}{|c|c|c|c|c|c|c|}
\hline & \multicolumn{3}{|c|}{ Kolmogorov-Smirnov } & \multicolumn{3}{|c|}{ Shapiro-Wilk } \\
\hline & Statistic & df & Sig. & Statistic & $\mathrm{df}$ & Sig. \\
\hline Unstandardized Residual & , 133 & 40 & ,071 & ,931 & 40 & ,017 \\
\hline
\end{tabular}

Lilliefors Significance Correction.

Berdasarkan pengujian di atas, nilai signifikansi testpada variabel residual tidak terstandardisasi (unstandardized residuals) menggunakan uji Kolmogorov - Smirnovv menghasilkan tingkat signifikansi (AsympSig. (2-tailed) sebesar 0,133>0,05, sehingga dapat disimpulkan bahwa data penelitian memiliki tingkat distribusi normal.

\section{Uji Multikolinearitas}

Tabel 10. Uji Multikolinearitas

\begin{tabular}{|c|c|c|c|}
\hline & \multirow{2}{*}{ Model } & \multicolumn{2}{|c|}{ Collinearity Statistics } \\
\hline & & Tolerance & VIF \\
\hline 1 & Kompetensi & ,858 & 1,166 \\
\hline
\end{tabular}




\begin{tabular}{lr|r}
\hline Disiplin &, 658 & 1,520 \\
\cline { 2 - 3 } &, 580 & 1,723 \\
\hline
\end{tabular}

a. Dependent Variable: Kinerja Pegawai

Berdasarkan tabel di atas, dapat dilihat bahwa nilai VIF $<10$ artinya secara keseluruhan variabel bebas tidak terjadi gejala multikolinearitas.

\section{Uji Heteroskedastisitas}

Tabel 11. Uji Heteroskedastisitas

\begin{tabular}{|c|c|c|c|c|c|c|}
\hline \multirow[b]{2}{*}{ Model } & & \multicolumn{2}{|c|}{ Unstandardized Coefficients } & \multirow{2}{*}{$\begin{array}{c}\text { Standardized } \\
\text { Coefficients } \\
\text { Beta }\end{array}$} & \multirow[b]{2}{*}{$\mathrm{t}$} & \multirow[b]{2}{*}{ Sig. } \\
\hline & & B & Std. Error & & & \\
\hline \multirow[t]{4}{*}{$\overline{1}$} & (Constant) & 6,708 & 3,165 & & 2,119 & $\overline{041}$ \\
\hline & Kompetensi &,- 023 & ,071 &,- 054 &,- 329 & $\overline{, 744}$ \\
\hline & Disiplin &,- 040 & ,032 &,- 233 & $-1,242$ & 222 \\
\hline & $\overline{\text { Motivasi Kerja }}$ &,- 081 & ,078 &,- 207 & $-1,039$ & ,306 \\
\hline
\end{tabular}

a. Dependent Variable: Residual

Masing-masing Variabel bebas memiliki nilai signifikansi (sig 2-tailed) $>0,05$ terhadap nilai residual dari variabel kinerja (Y) sehingga dapat diartikan semua variabel bebas tidak mengalami gejala heteroskedastisitas.

\section{Analisis Regresi Linear Berganda}

Berdasarkan perhitungan menggunakan IBM SPSS Statistics 23 diperoleh output sebagai berikut :

Tabel 12. Analisis Regresi Linear

\begin{tabular}{|c|c|c|c|c|c|c|}
\hline \multirow[b]{2}{*}{ Model } & & \multicolumn{2}{|c|}{ Unstandardized Coefficients } & \multirow{2}{*}{$\begin{array}{l}\text { Standardized } \\
\text { Coefficients } \\
\text { Beta }\end{array}$} & \multirow[b]{2}{*}{$\mathrm{t}$} & \multirow[b]{2}{*}{ Sig. } \\
\hline & & $\mathrm{B}$ & Std. Error & & & \\
\hline$\overline{1}$ & (Constant) & 4,654 & 5,153 & & 903 &, 372 \\
\hline
\end{tabular}




\begin{tabular}{ll|l|l|l|l}
\hline Kompetensi &, 435 &, 116 &, 401 & 3,751 &, 001 \\
\hline Disiplin &, 137 &, 053 &, 318 & 2,601 &, 013 \\
\hline Motivasi Kerja &, 346 &, 127 &, 354 & 2,723 &, 010 \\
\hline
\end{tabular}

a. Dependent Variable: Kinerja Pegawai

Model persamaan regresi linier berganda berdasarkan tabel diatas adalah sebagai berikut :

Persamaan Regresi $Y=4,564+0,435 X_{1}+0,137 X_{2}+0,346 X_{3}$

Y= Kinerja

$\mathrm{X} 1=$ Kompetensi

X2= Disiplin Kerja

X3= Motivasi Kerja

Tabel 13. Koefesien Model

\begin{tabular}{rr|r|r|r}
\hline Model & R & R Square & Adjusted R Square & \multicolumn{2}{c}{$\begin{array}{c}\text { Std. Error of the } \\
\text { Estimate }\end{array}$} \\
\hline 1 &, $804^{\mathrm{a}}$ &, 647 &, 617 & 1,496 \\
\hline
\end{tabular}

a. Predictors: (Constant), Motivasi Kerja, Kompetensi, Disiplin

\section{Pengujian Hipotesis}

\section{Hipotesis Parsial}

Nilai t tabel yang dijadikan acuan minimal adalah menggunakan nilai $\mathrm{DF}=40-2=38$ didapat nilai t tabel acuan sebesar 1,685. Pengujian secara parsial untuk membuktikan hipotesis 1 sampai dengan hipotesis 4 diperoleh hasil sebagai berikut :

Tabel 14. Uji Hipotesis Parsial

\begin{tabular}{|c|c|c|c|c|c|c|}
\hline \multirow[b]{2}{*}{ Model } & & \multicolumn{2}{|c|}{$\begin{array}{c}\text { Unstandardized } \\
\text { Coefficients }\end{array}$} & \multirow{2}{*}{$\begin{array}{c}\text { Standardized } \\
\text { Coefficients } \\
\text { Beta }\end{array}$} & \multirow[b]{2}{*}{$\mathrm{t}$} & \multirow[b]{2}{*}{ Sig. } \\
\hline & & B & Std. Error & & & \\
\hline \multirow[t]{4}{*}{1} & (Constant) & 4,654 & 5,153 & & ,903 & $\overline{, 372}$ \\
\hline & Kompetensi & ,435 & ,116 & ,401 & 3,751 & $\overline{, 001}$ \\
\hline & Disiplin & ,137 & ,053 & ,318 & 2,601 & $\overline{, 013}$ \\
\hline & Motivasi kerja & ,346 &, 127 & ,354 & 2,723 & $\overline{, 010}$ \\
\hline
\end{tabular}

a. Dependent Variable: Kinerja Pegawai

a. Hipotesis 1 : terdapat pengaruh signifikan kompetensi (X1) terhadap kinerja pegawai (Y) dengan hipotesis Statistik sebagai berikut: 


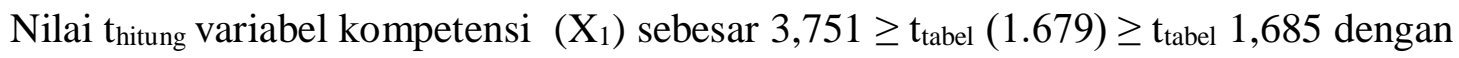
tingkat signifikansi 0,029 $(\mathrm{p}<0,05)$. Dari hasil tersebut maka Ho ditolak dan berarti Ha diterima. Berarti Hipotesis 1 yang berbunyi terdapat pengaruh signifikan antara kompetensi terhadap kinerja pegawai DAPAT DITERIMA.

b. Hipotesis 2: terdapat pengaruh signifikan disiplin kerja (X2) terhadap kinerja pegawai Setda Kabupaten Cirebon (Y) dengan hipotesis Statistik sebagai berikut:

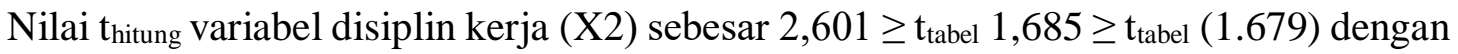
tingkat signifikansi 0,036 $(\mathrm{p}<0,05)$. Dari hasil tersebut maka Ho ditolak dan berarti Ha diterima. Berarti Hipotesis 2 yang berbunyi terdapat pengaruh signifikan antara disiplin kerja terhadap kinerja pegawai DAPAT DITERIMA.

c. Hipotesis 3: terdapat pengaruh signifikan motivasi kerja (X3) terhadap kinerja pegawai (Y) dengan hipotesis Statistik sebagai berikut:

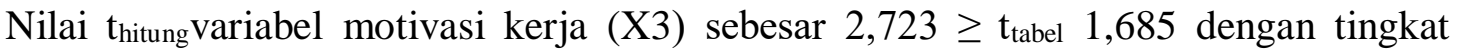
signifikansi 0,00 $(\mathrm{p}<0,05)$. Dari hasil tersebut maka Ho ditolak dan berarti Ha diterima. Berarti Hipotesis 3 yang berbunyi terdapat pengaruh signifikan antara motivasi kerja terhadap kinerja pegawai DAPAT DITERIMA.

\section{Pengujian Hipotesis Simultan (Hipotesis 4)}

Hipotesis 4: terdapat pengaruh positif dan signifikan kompetensi (X1), disiplin kerja (X2) dan motivasi kerja (X3) secara bersama-sama (simultan) terhadap kinerja pegawai (Y) dengan hipotesis statistik sebagai berikut:

$\mathrm{H}_{0}$ : X1, X2, X3 secara bersama-sama tidak berpengaruh terhadap $\mathrm{Y}$, jika $\mathrm{f}_{\text {hitung }}<\mathrm{f}_{\text {tabel }}$ atau sig $>0,05$.

Hasil Pengujian pada tabel anova untuk melihat nilai koefisien $f_{\text {hitung dan tingkat }}$ signifikansinya dapat dilihat sebagai berikut :

Tabel 15. Tabel Anova

\begin{tabular}{|c|c|c|c|c|c|c|}
\hline \multicolumn{7}{|c|}{$\mathrm{ANOVA}^{\mathrm{a}}$} \\
\hline Model & & Sum of Squares & df & Mean Square & $\mathrm{F}$ & Sig. \\
\hline \multirow[t]{3}{*}{1} & Regression & 147,447 & 3 & 49,149 & 21,972 &, $000^{\mathrm{b}}$ \\
\hline & Residual & 80,528 & 36 & 2,237 & & \\
\hline & Total & 227,975 & 39 & & & \\
\hline
\end{tabular}

Berdasarkan hasil perhitungan menggunakan software SPSS, didapat nilai $f$ hitung $=$ $21,972>f_{\text {tabel }}=2,87$ dengan tingkat signifikansi uji f sebesar $0,000(\mathrm{p}<0.05)$ Dari hasil 
tersebut maka Ho ditolak dan berarti Ha diterima. Artinya HIPOTESIS 4 yang diujikan yaitu variabel kompetensi, disiplin kerja dan motivasi kerja secara bersama-sama mempunyai pengaruh positif dan signifikan terhadap kinerja pegawai Cirebon DAPAT DITERIMA.

\section{Pembahasan}

\section{Kompetensi terhadap Kinerja}

Pencapaian kinerja pegawai didukung oleh beberapa faktor, diantaranya kompetensi, disiplin kerja dan motivasi kerja. Berdasarkan hasil statistik menunjukkan bahwa kompetensi mempengaruhi kinerja pegawai dengan angka koefesien 0,435 . Besarnya pengaruh variabel adalah $99,2 \%$.

\section{Disiplin kerja terhadap Kinerja}

Berdasarkan hasil statistik menunjukkan bahwa disiplin kerja mempengaruhi kinerja pegawai dengan angka koefesien 0,137.

\section{Motivasi kerja dan Kinerja}

Motivasi kerja dalam sebuah organisasi merupakan hal penting dalam menjalankan operasional organisasi. Out put dari motivasi kerja di anataranya kinerja pegawai. Berdasarkan hasil statistik menunjukkan bahwa dukungan manajemen mempengaruhi kinerja pegawai dengan angka koefesien 0,346.

\section{Pengaruh Simultan Variabel Bebas terhadap Variabel Independen}

Berdasarkan perhitungan statistik, ke tiga variabel bebas yakni kompetensi, disiplin kerja dan motivasi kerja bersama-sama memiliki pengaruh terhadap kinerja pegawai. Variabel yang memiliki pengaruh yang paling besar adalah kompetensi dengan angka koefisien 0,435. Berikutnya adalah variabel motivasi kerja dengan angka koefisien 0,346 . Terakhir variabel disiplin kerja dengan angka koefisien 0,137. 


\section{KESIMPULAN DAN IMPLIKASI}

1. Kompetensi memiliki pengaruh positif dan signifikan terhadap kinerja pegawai. Dalam hal ini, semakin baik kompetensi, tentunya akan meningkatkan kinerja. Dan begitu pula sebaliknya, jika kompetensi yang dimiliki buruk maka akan menurunkan kinerja pegawai.

2. Disiplin kerja memiliki pengaruh positif dan signifikan terhadap kinerja pegawai. Dalam hal ini, semakin baik disiplin, tentunya akan meningkatkan kinerja. Dan begitu pula sebaliknya, jika disiplin yang dimiliki buruk maka akan menurunkan kinerja pegawai.

3. Motivasi kerja memiliki pengaruh positif dan signifikan terhadap kinerja pegawai. Dalam hal ini, semakin baik motivasi kerja, tentunya akan meningkatkan kinerja. Dan begitu pula sebaliknya, jika motivasi kerja yang dimiliki buruk maka akan menurunkan kinerja pegawai.

4. Secara simultan, ketiga variabel yang diteliti yaitu kompetensi, disiplin kerja dan motivasi kerja bepengaruh positif dan signifikan terhadap kinerja pegawai. Faktor yang paling tinggi pengaruhnya adalah kompetensi, motivasi kerja terakhir disiplin kerja. Total kontribusi perubahan yang diberikan dari ketiga variabel tersebut secara simultan adalah sebesar 80,4\%, dan pengaruh lainnya berasal dari faktor lain di luar kerangka penelitian.

Penelitian ini masih memiliki keterbasan di mana belum mengungkapkan seluruh variabel yang dapat mempengaruhi kinerja pegawai. Selain itu penelitian ini belum menjelaskan dampak spesifik dari sudut pandang kinerja secara utuh. Untuk peneliti yang ingin melanjutkan penelitian pada bidang yang sama perlu melakukan pengamatan yang lebih mendalam tentang variabel-variabel yang berpengaruh terhadap kinerja atau dapat juga menggunakan model kerangka berpikir yang berbeda.

\section{DAFTAR PUSTAKA}

Ambar T. Sulistiyani dan Rosidah, Manajemen Sumber Daya Manusia: Konsep, Teori dan Pengembangan dalam Konteks Organisasi Publik, (Yogyakarta: Graha Ilmu, 2013), h. 236.

Ghozali, Imam. (2013). Analisis Multivariate dengan program IBM SPSS 21 edisi ketujuh. Semarang: Badan Penerbit Universitas Diponegoro. 
Ghozali, Imam (2016). Aplikasi Analisis Multivariete Dengan Program IBM SPSS 23 edisi kedelapan. Semarang : Badan Penerbit Universitas Diponegoro.

Kumara, W., dan Utama, W,. (2016). Pengaruh Pelatihan Terhadap Kinerja Karyawan Dengan Mediasi Kepemimpinan Pad Hotel Satriya Cottages Kuta-Bali. E-Jurnal Manajemen Unud, Vol. 5, No.3.

Mangkunegara, A.A. A. P. (2011). Manajemen Sumber Daya Manusia, Pengertian Dasar, Pengertian dan Masalah,(Edisi Revisi). Bandung: Penerbit PT.Remaja Rosda Karya.

Mangkunegara, Anwar Prabu. 2017. Manajemen Sumber Daya Manusia Perusahaan. Bandung : PT. Remaja Rosdakarya.

Pomalingo, Rivky; Silvya L Mandey; Yantje Uhing. 2015. Pengaruh Disiplin Kerja, Kompetensi, dan Motivasi terhadap Kinerja Pegawai pada Kantor Badan Penanggulangan Bencana Daerah Provinsi Sulawesi utara. Jurnal Berkala Ilmiah Efisiensi Volume 15 No. 05 Tahun 2015.

Rivai, Veithzal dan Ella. 2011. Manajemen Sumber Daya Manusia. Jakarta : PT. Raja Grafindo Persada.

Rivai, V. (2015). Manajemen Sumber Daya Manusia Untuk Perusahaan: Dari Teori ke Praktik, (Edisi Pertama). Jakarta: Raja Grafindo Perkasa.

Sidanti, Heny. (2015). "Pengaruh Lingkungan Kerja, Disiplin Kerja dan Motivasi Kerja terhadap Kinerja Pegawai Negeri Sipil Sekretariat DPRD Kabupaten Madiun”, Jurnal JIBEKA, Volume 9. No. 1. 2015.

Sinambela, Lijan poltak. "Kinerja pegawai teori pengukuran dan implikasi", Graha ilmu, Yogyakarta, 2012.

Sinambela, Lijan Poltak. (2016:335). Manajemen Sumber Daya Manusia. Jakarta: PT Bumi Aksara. 
Surjosuseno, Daniel. 2015. "Pengaruh Lingkungan Kerja dan Motivasi Kerja terhadap Kinerja Karyawan pada Bagian Produksi UD. Pabrik Ada Plastic". Jurnal AGORA. Vol. 3 No. 2. Surabaya.

Wibowo, 2013. Manajemen Kinerja. Jakarta : PT. Raja Grafindo Persada. 